\title{
Analisa Stabilitas Timbunan Jalan Berdsarkan Instrumen Geoteknik pada Proyek Pembangunan Relokasi Jalan Tol Surabaya-Gempol, Paket 3A STA 40+950 - 42+200: Ruas Porong - Gempol
}

\author{
Nurul Nisaqolifatul Uyun, Noor Endah dan Putu Tantri Kumala Sari
}

Departemen Teknik Sipil, Fakultas Teknik Sipil dan Perencanaan, Institut Teknologi Sepuluh Nopember (ITS) e-mail : tantrigeoteknik@gmail.com

\begin{abstract}
Abstrak - Jalan tol Porong - Gempol adalah merupakan relokasi jalan akibat lumpur lapindo. Dalam proyek pembangunan jalan tol ini terdapat 2 paket pekerjaan yaitu paket 3A dan 3B. Pada tahun 2014 terjadi kelongsoran tanah timbunan pada paket 3B. Dengan adanya kejadian kelongsoran tersebut dikhawatirkan akan terjadi kelongsoran serupa pada tanah timbunan paket $3 \mathrm{~A}$ mengingat tinggi timbunan pada pekerjaan paket 3A maupun 3B yang hampir sama dan dibangun pada kondisi tanah dasar lunak. Dalam studi ini dilakukan analisa stabilitas timbunan menggunakan program bantu, analisis kelongsoran dengan data instrumen geoteknik (inclinometer, pneumatic piezometer, dan settlement plate) dan perencanaan perkuatan menggunakan sheet pile dan micropile. Berdasarkan hasil analisis instrumen geoteknik yang dilakukan, pemampatan pada tanah dasar di bawah tanah timbuanan paket $3 \mathrm{~A}$ sudah dapat dikatakan selesei dengan derajat konsolidasi lebih dari $90 \%$; jadi kondisi timbunan pada paket 3A dapat dikatakan stabil dan tidak ada bahaya longsor. Akan tetapi hasil analisa stabilitas timbunan dengan menggunakan program bantu menunjukkan nilai SF 0,898 yang berarti kurang dari SF rencana atau dalam kondisi tidak aman. Oleh karena itu timbunan pada paket 3A direncanakan untuk diberi perkuatan dengan menggunakan sheetpile tipe W-500-A-1000 sebanyak 5 buah sedalam $13 \mathrm{~m}$ atau micropile diameter $600 \mathrm{~mm}$ sebanyak 5 buah sedalam 13 m.
\end{abstract}

Kata Kunci-Stabilitas timbunan, Instrumen Geoteknik, Sheet Pile, Micropile

\section{PENDAHULUAN}

$\mathbf{J}_{\mathrm{t}+\mathrm{N}}$ ALAN tol Porong-Gempol merupakan bagian dari jalan tol Trans-Jawa. Jalan tol Porong- Gempol dibangun sepanjang $10 \mathrm{~km}$ dan merupakan akses baru hasil relokasi akibat lumpur Lapindo. Pembangunan jalan tol PorongGempol ini dibagi menjadi 2 paket pekerjaan yaitu paket $3 \mathrm{~A}$ dan 3B. Pekerjaan paket 3A dimulai pada STA 39.250 46.650 dan pekerjaan paket 3B dimulai pada STA 46.650 48.366,50.

Pada tahun 2014 telah terjadi kelongsoran pada paket 3B. Kejadian kelongsoran pada tanah timbunan paket 3B ini dikhawatirkan juga akan terjadi pada tanah timbunan paket $3 \mathrm{~A}$ mengingat tinggi timbunan pada pekerjaan paket $3 \mathrm{~A}$ maupun 3B yang hampir sama yaitu sekitar 7 meter dan dibangun pada kondisi tanah dasar yang sama-sama lunak.

Oleh karena itu perlu di analisa stabilitas tanah timbunan. Selain itu diperlukan alternatif perkuatan yang cocok agar tidak terjadi kelongsoran pada paket 3A. Di lapangan telah dilakukan monitoring dan didapatkan data instrumen geoteknik. Data instrumen geoteknik berupa data inclinometer, piezometer, dan settlement plate. Berdasarkan data instrumen geoteknik tersebut, dapat dibandingkan antara hasil perhitungan rumusan empiris yang dilakukan dalam perencanaan terhadap kondisi sesungguhnya yang ada di lapangan. Selain itu dapat dicari penyebab kelongsororan paket 3B dan mengapa paket 3A belum longsor.

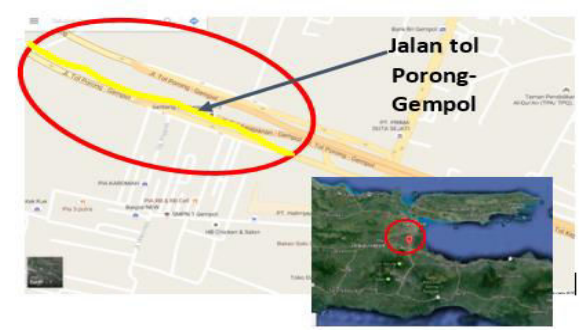

Gambar 1. Peta Lokasi Studi.

\section{METODOLOGI}

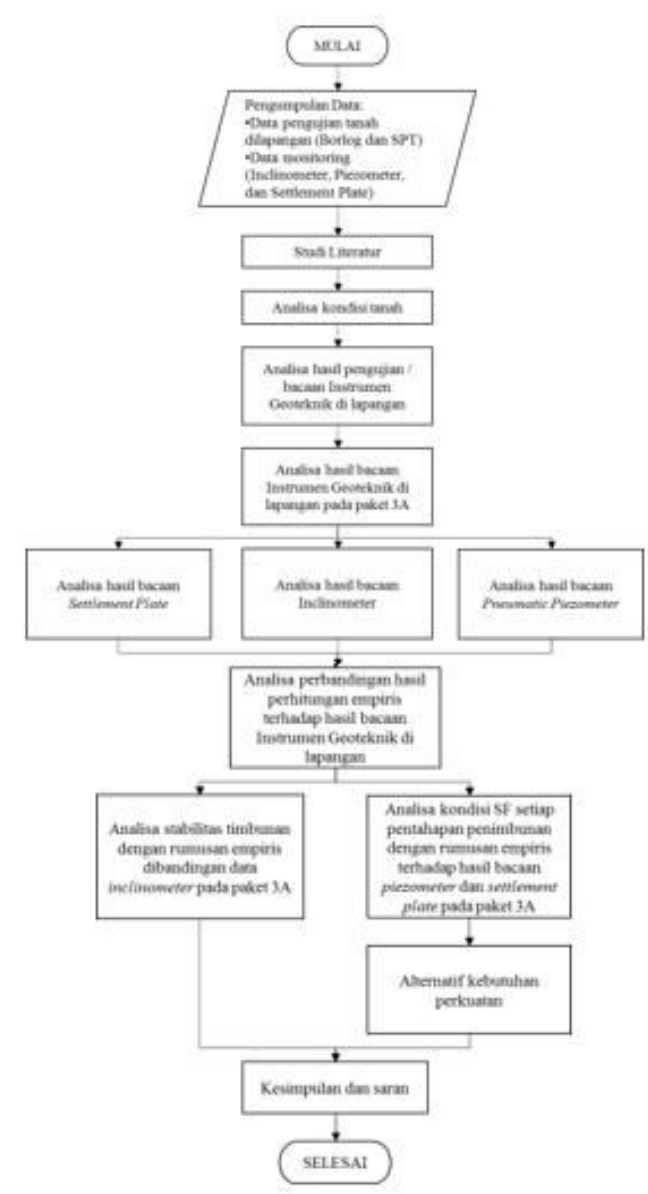

Gambar 2. Diagram Alir Metodologi Perencanaan. 


\section{HASIL DAN PEMBAHASAN}

\section{A. Data Tanah Lapangan}

Data tanah yang digunakan dalam Studi ini adalah data lapangan yaitu sondir dan N-SPT pada proyek pembangunan relokasi jalan Tol Porong-Gempol paket 3A STA 40+95042+200. Data tersebut diperoleh dari PT. Teknindo Geosistem Unggul pada tahun 2014. Data tanah lapangan yang ada meliputi 16 data sondir dan 3 data N-SPT.

Kemudian dilakukan statigrafi dari data sondir dan N-SPT untuk mengetahui kondisi tanah dan konsistensi tanah [1][2]. Diakrenakan terlalu panjang maka dibagi menjadi 3 potogan yaitu:

1. Potongan I yaitu mulai dari STA 40+950 - STA $41+250$ (area biru).

2. Potongan II STA $41+350$ - STA $41+710$ (area merah).

3. Potongan III STA $41+750$ - STA 42+200 (area kuning).

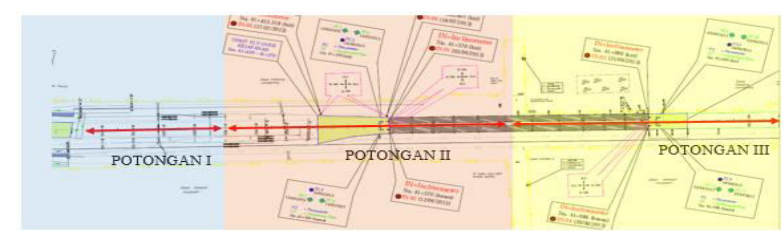

Gambar 3. Denah statigrafi.

Berikut adalah rekap hasil konsistensi tanah berdasarkan statigrafi data sondir dan N-SPT:

Tabel 1.

Kosnsistensi tanah Potongan I

\begin{tabular}{|l|r|r|r|r|}
\hline \multicolumn{1}{|c|}{ STA } & STA 40+950 & STA 41+050 & \multicolumn{1}{c|}{ STA 41+150 } & \multicolumn{1}{c|}{ STA 41+250 } \\
\hline Karakteristik tanah & \multicolumn{1}{c|}{$\mathrm{s} 1$} & \multicolumn{1}{c|}{$\mathrm{s} 2$} & \multicolumn{1}{c|}{$\mathrm{s} 3$} & \multicolumn{1}{c|}{$\mathrm{s} 4$} \\
\hline Sangat lunak (Very Soft) & $0-6 \mathrm{~m}$ & $0-5.2 \mathrm{~m}$ & $0-2.4 \mathrm{~m}$ & $0-9.6 \mathrm{~m}$ \\
\hline Lunak (Soft) & $6-6.4 \mathrm{~m}$ & $5.2-5.6 \mathrm{~m}$ & $2.4-4.8 \mathrm{~m}$ & $9.6-13.6 \mathrm{~m}$ \\
\hline Sedang (Medium) & $6.4-10.8 \mathrm{~m}$ & $5.6-16.4 \mathrm{~m}$ & $4.8-14.8 \mathrm{~m}$ & $13.6-19.2 \mathrm{~m}$ \\
\hline Kaku (Stiff) & $15.6-19.4 \mathrm{~m}$ & $16.4-19 \mathrm{~m}$ & $14.8-17.6 \mathrm{~m}$ & $19.2-20 \mathrm{~m}$ \\
\hline Sangat kaku (Very Stiff) & & & $17.6-20.8 \mathrm{~m}$ & $20-22 \mathrm{~m}$ \\
\hline Keras (Hard) & $>19,4 \mathrm{~m}$ & $>19 \mathrm{~m}$ & $>20.8 \mathrm{~m}$ & $>22 \mathrm{~m}$ \\
\hline
\end{tabular}

Tabel 2.

Konsistensi tanah Potongan II

\begin{tabular}{|l|r|r|r|r|r|}
\hline \multicolumn{1}{|c|}{ STA } & \multicolumn{1}{|c|}{ STA 41+350 } & STA 41+450 & STA 41+570 & \multicolumn{1}{l}{ STA 41+635 } & STA 41+710 \\
\hline Karakteristik tanah & \multicolumn{1}{c}{$\mathrm{s} 5$} & \multicolumn{1}{c}{$\mathrm{s} 6$} & \multicolumn{1}{c|}{$\mathrm{s} 7$} & \multicolumn{1}{c}{$\mathrm{s} 8$} & \multicolumn{1}{c}{$\mathrm{s} 9$} \\
\hline Sangat lunak (Very Soft) & $0-5.6 \mathrm{~m}$ & $0-9.2 \mathrm{~m}$ & $0-10 \mathrm{~m}$ & $0-9.2 \mathrm{~m}$ & $0-9.6 \mathrm{~m}$ \\
\hline Lunak (Soft) & $5.6-10 \mathrm{~m}$ & $9.2-10.4 \mathrm{~m}$ & $10-11.2 \mathrm{~m}$ & $9.2-14.8 \mathrm{~m}$ & $9.6-16.4 \mathrm{~m}$ \\
\hline Sedang (Medium) & $10-17.2 \mathrm{~m}$ & $10.4-16.4 \mathrm{~m}$ & $11.2-17.2 \mathrm{~m}$ & $14.8-16.8 \mathrm{~m}$ & $16.4-16.8 \mathrm{~m}$ \\
\hline Kaku (Stiff) & $17.2-19.6 \mathrm{~m}$ & $16.4-18.8 \mathrm{~m}$ & $17.2-19.6 \mathrm{~m}$ & $16.8-18.4 \mathrm{~m}$ & $16.8-18.8 \mathrm{~m}$ \\
\hline Sangat kaku (Very Stiff) & $19.6-22 \mathrm{~m}$ & $18.8-20.8 \mathrm{~m}$ & $19.6-20.8 \mathrm{~m}$ & $18.4-20 \mathrm{~m}$ & $18.8-19.2 \mathrm{~m}$ \\
\hline Keras (Hard) & $>22 \mathrm{~m}$ & $>20.8 \mathrm{~m}$ & $>20.8 \mathrm{~m}$ & $>20 \mathrm{~m}$ & $>19.2 \mathrm{~m}$ \\
\hline
\end{tabular}

Tabel 3.

Konsistensi tanah Potongan III

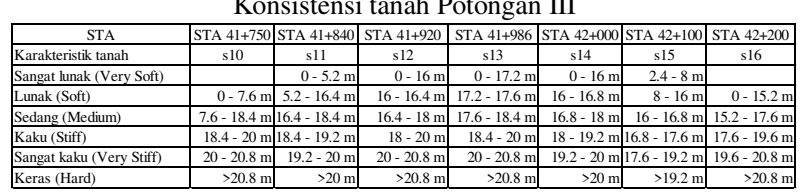

Parameter yang digunakan dalan Studi ini adalah sebagai berikut :

Tabel 4.

Data tanah STA $41+570$ (S7) STA $41+570$

\begin{tabular}{|c|c|c|c|c|c|}
\hline \multicolumn{6}{|c|}{ STA $41+570$} \\
\hline \multirow{2}{*}{ Karakteristik tanah } & \multirow{2}{*}{ Kedalaman } & \multirow{2}{*}{$\begin{array}{c}\mathrm{Qc} \\
(\mathrm{kg} / \mathrm{cm} 2)\end{array}$} & \multirow{2}{*}{$\begin{array}{c}\text { ysat } \\
(\mathrm{kN} / \mathrm{m} 3)\end{array}$} & \multicolumn{2}{|c|}{ Strength } \\
\hline & & & & $\Phi$ & $\mathrm{C}(\mathrm{kPa})$ \\
\hline Sangat lunak (Very Soft) & $0-10 \mathrm{~m}$ & 8 & 17 & 0 & 10 \\
\hline Lunak (Soft) & $10-11.2 \mathrm{~m}$ & 14 & 17 & 0 & 18 \\
\hline Sedang (Medium) & $11.2-17.2 \mathrm{~m}$ & 37 & 17 & 0 & 48 \\
\hline Kaku (Stiff) & $17.2-19.6 \mathrm{~m}$ & 57 & 17 & 0 & 75 \\
\hline
\end{tabular}

\section{B. Data Tanah Timbunan}

Pada Studi ini menggunakan material timbunan dengan spesifikasi teknis sebagai berikut :

- $\quad$ Sifat fisik tanah timbunan :

$$
\begin{array}{ll}
\gamma \text { sat } & =1,75 \mathrm{t} / \mathrm{m} 3 \\
\gamma \text { timb } & =1,75 \mathrm{t} / \mathrm{m} 3 \\
\mathrm{C} & =0 \\
\Phi & =30
\end{array}
$$

- Geometri Timbunan :

Tinggi tanah timbunan $\left(\mathrm{H}_{\text {final }}\right)$ yang direncanakan yaitu sebesar 6 meter dengan lebar jalan adalah 56 meter.

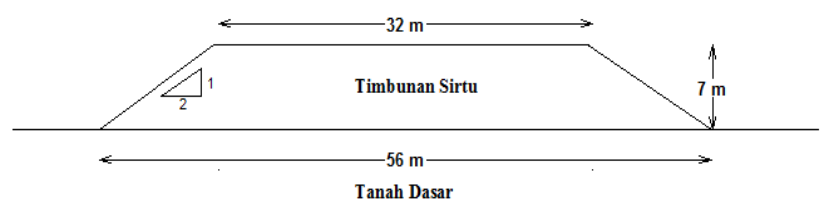

Gambar 4. Sketsa Rencana Penimbunan

\section{Analisis Settlement Plate}

Data Settlement Plate berupa data penurunan tanah untuk dasar apakah tanah tersebut masih mengalami penurunan atau sudah mengalami penurunan akhir (final settlemnet). Untuk mengetahui prediksi penurunan akhir tiap Settlement Plate, maka dilakukan dengan menggunakan Metode Asaoka. Berikut adalah grafik penentuan settlement akhir pada tiap settlement plate.

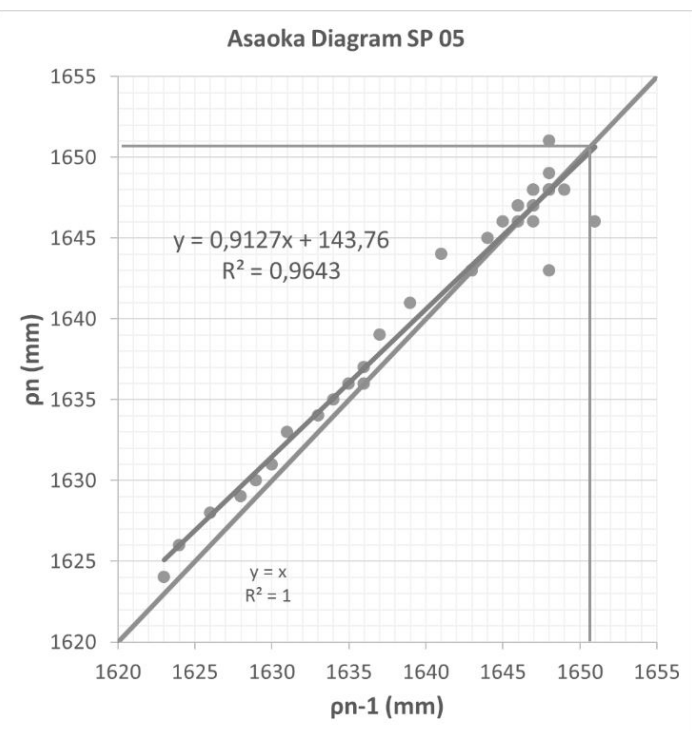

Gambar 5. Kurva Penentuan Settlement Akhir SP-05

Perhitungan penentuan total pemampatan akhir di ambil sebagai contoh adalah pada SP-05. Pada kurva penentuan settlement akhir SP-05 diperoleh sebuah persamaan dari grafik yang telah dibuat. Dari persamaan tersebut dapat ditentukan nilai dari total settlement sebagai berikut:

$$
\begin{array}{ll}
\mathrm{y}=0,9127 \mathrm{x} & +143,76 \\
\mathrm{y}-0,9127 \mathrm{x} & =143,76 \\
\mathrm{y}-\mathrm{x} & =0 \\
0,0873 \mathrm{x} & =143,76 \\
\mathrm{x} & =1647
\end{array}
$$

Sehingga didapatkan nilai total settlement akhir pada SP05 adalah sebesar $1647 \mathrm{~mm}$. Setelah didapatkan prediksi 
total settlement akhir, maka sisa settlement di lapangan dapat diketahui dengan cara sebagai berikut:

Sc bacaan akhir settlement plate

$$
\begin{aligned}
= & 1643 \mathrm{~mm} \\
= & 1647 \mathrm{~mm} \\
= & \text { final settlement } \\
& \text { bacaan settlement } \\
= & 1647-1643 \\
= & 4 \mathrm{~mm}
\end{aligned}
$$

Maka sisa settlement yang terjadi adalah sebesar $4 \mathrm{~mm}$. Sisa pemampatan pada Settlement Plate lainnya dapat dilihat pada Tabel 5 .

Tabel 5.

Sisa Settlement Titik Settlement Plate

\begin{tabular}{|c|c|c|c|c|}
\hline \multirow{2}{*}{ No } & \multirow{2}{*}{$\begin{array}{c}\text { Settlement } \\
\text { Plate }\end{array}$} & $\begin{array}{c}\text { kumulatif settlement } \\
\text { lapangan }\end{array}$ & $\begin{array}{c}\text { prediksi settlement } \\
\text { final }\end{array}$ & $\begin{array}{c}\text { sisa } \\
\text { settlement }\end{array}$ \\
\cline { 3 - 5 } & Sct (mm) & S $\propto(\mathrm{mm})$ & $(\mathrm{mm})$ \\
\hline 1 & SP 05 & 1643 & 1647 & 4 \\
\hline 2 & SP 06 & 1513 & 1518 & 5 \\
\hline 3 & SP 07 & 1474 & 1477 & 3 \\
\hline 4 & SP 08 & 1433 & 1445 & 12 \\
\hline 5 & SP 09 & 1436 & 1445 & 9 \\
\hline 6 & SP 10 & 1437 & 1460 & 23 \\
\hline 7 & SP 11 & 1254 & 1266 & 12 \\
\hline 8 & SP 12 & 1280 & 1359 & 79 \\
\hline
\end{tabular}

Sehingga dari hasil diatas dapat dilihat besar sisa penurunan pada masing-masing Settlement Plate diperkirakan berkisar $3 \mathrm{~mm}-79 \mathrm{~mm}$.

Tabel 6.

Rekap Nilai Final Settlement Plate dan Derajat Konsolidasi (U) Aktual

\begin{tabular}{|c|c|c|c|c|}
\hline \multirow{2}{*}{ No } & \multirow{2}{*}{$\begin{array}{c}\text { Settlement } \\
\text { Plate }\end{array}$} & $\begin{array}{c}\text { kumulatif settlement } \\
\text { lapangan }\end{array}$ & $\begin{array}{c}\text { prediksi settlement } \\
\text { final }\end{array}$ & $\begin{array}{c}\text { derajat } \\
\text { konsolidasi } \\
\text { aktual }\end{array}$ \\
\cline { 3 - 5 } & Sct (mm) & Sœ(mm) & U \% \\
\hline 1 & SP 05 & 1643 & 1647 & $99,76 \%$ \\
\hline 2 & SP 06 & 1513 & 1518 & $99,67 \%$ \\
\hline 3 & SP 07 & 1474 & 1477 & $99,80 \%$ \\
\hline 4 & SP 08 & 1433 & 1445 & $99,17 \%$ \\
\hline 5 & SP 09 & 1436 & 1445 & $99,38 \%$ \\
\hline 6 & SP 10 & 1437 & 1460 & $98,42 \%$ \\
\hline 7 & SP 11 & 1254 & 1266 & $99,05 \%$ \\
\hline 8 & SP 12 & 1280 & 1359 & $94,19 \%$ \\
\hline
\end{tabular}

Sehingga hasil analisa derajat konsolidasi aktual pada pemampatan akhir setiap Settlement Plate lebih dari 90\% atau dapat dikatakan pemampatan sudah selsei.

Derajat konsolidasi $>90 \%$

$$
99,76 \%>90 \% \quad(\mathrm{OK})
$$

\section{Analisis Inclinometer}

Besarnya displacement pada Grafik IN-01 (Gambar 6) dapat dilihat berdasarkan plot koordinat IN-01 pada Gambar 7. Displacement terbesar terjadi pada kedalaman 8 meter dengan maksimal displacement sebesar 123,400 mm pada tanggal 29 Juni 2013. Salah satu syarat kestabilan tanah timbunan dengan inclinometer adalah delta $(\Delta)$ displacement yang terjadi tiap interval yang sama adalah $\Delta 3<\Delta 2<\Delta 1$. Oleh karena itu data displacement yang dianalisa adalah mulai tanggal 26 Juni hingga 29 Juni 2013.

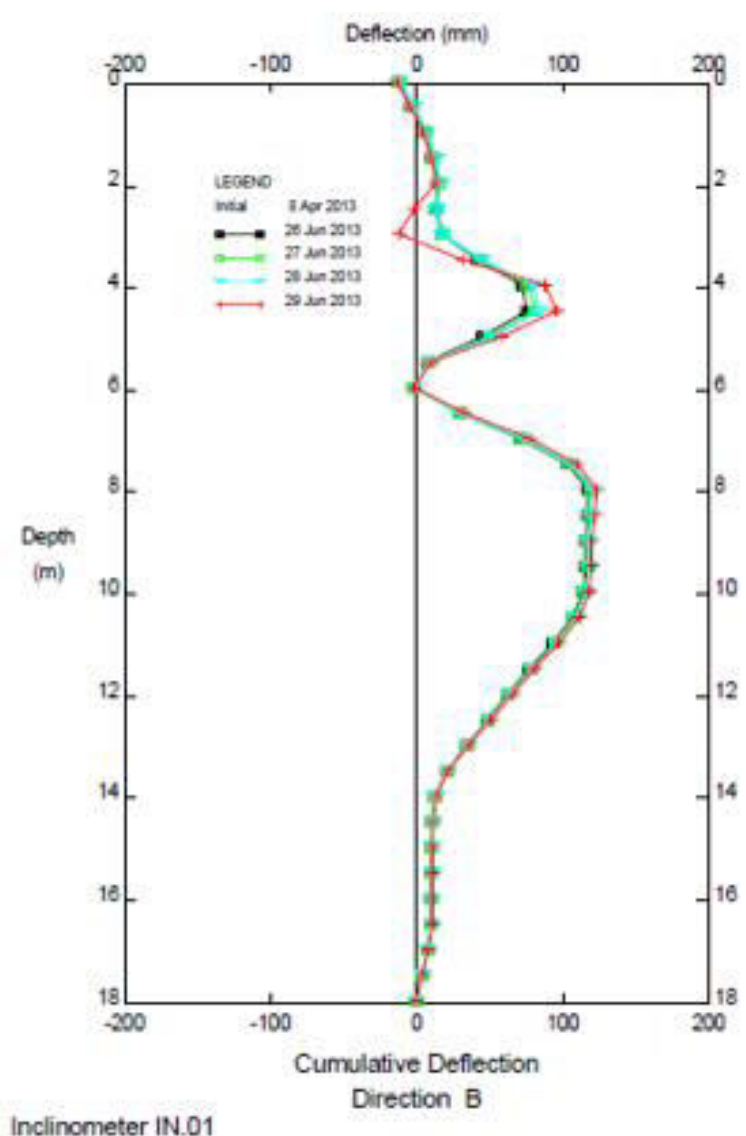

Gambar 6. Grafik displacement IN - 01

(Sumber: PT. Teknindo Geosistem Unggul)

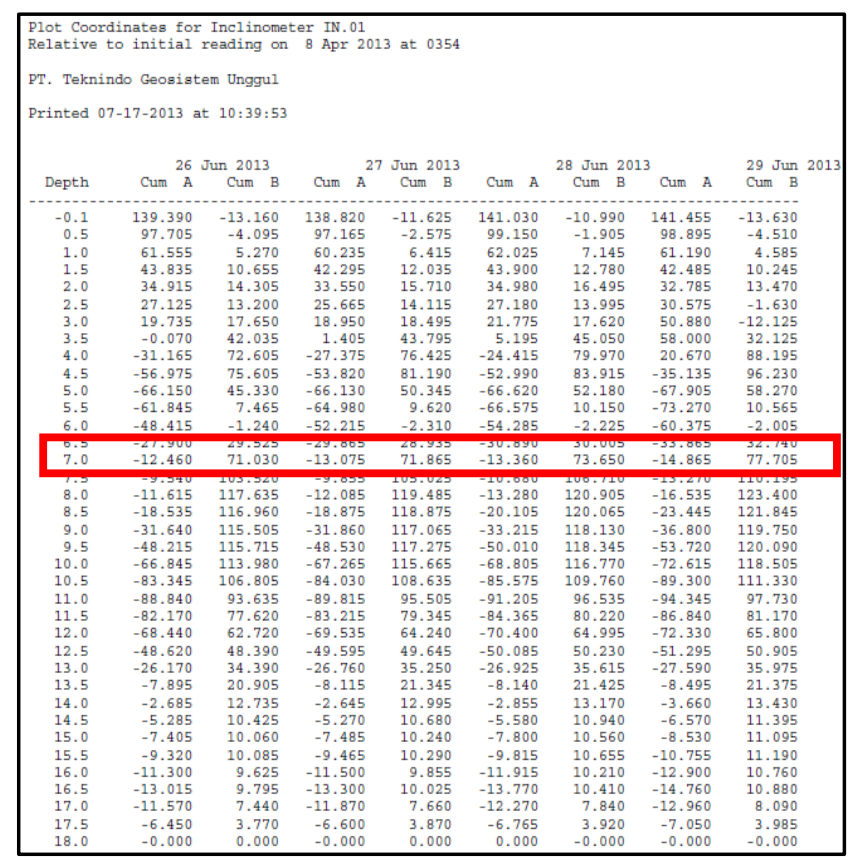

Gambar 7. Plot Koordinat IN - 01

(Sumber: PT. Teknindo Geosistem Unggul)

Berikut ini adalah hasil pehitungan analisa delta $(\Delta)$ displacement yang terjadi pada kedalaman 8 meter dengan waktu 1 harian dapat dilihat pada Tabel 7. 
Tabel 7.

Hasil cek kestabilan IN -01

\begin{tabular}{|c|c|c|c|}
\hline Tanggal & Depth (m) & Max deflex (mm) & $\Delta$ (delta) (mm) \\
\hline 26 Juni 2013 & 8 & 117,635 & \\
\hline 27 Juni 2013 & 8 & 119,485 & 1,850 \\
\hline 28 Juni 2013 & 8 & 120,905 & 1,420 \\
\hline 29 Juni 2013 & 8 & 123,400 & 2,495 \\
\hline
\end{tabular}

Dari tabel tersebut diperoleh besarnya $\Delta 3$ sebesar 1,85 $\mathrm{mm}, \Delta 2$ sebesar $1,42 \mathrm{~mm}$ dan $\Delta 1$ sebesar 2,495.

Sehingga,

$$
\begin{aligned}
& \Delta 3<\Delta 2<\Delta 1 \\
& 1,85<1,42<2,495 \quad(\mathrm{OK})
\end{aligned}
$$

Selanjutnya adalah melakukan cek kestabilan tanah timbunan berdasarkan inclinometer syarat kedua yaitu $\mathrm{Y}=$ Yaktual/Yzmax $\leq 1.3$ dimana $Y \max =0.16 \mathrm{x}$ Smax. Yaktual pada IN- 01 diperoleh dari bacaan inclinometer yang mempunyai displacement maksimal yaitu pada tanggal 29 Juni 2013 pada kedalaman 8 meter sebesar 123,400 meter. Kemudian untuk memperoleh Ymax maka perlu diketahui Smax (total pemampatan secara teoritis). Setelah dilakukan perhitungan pemampatan (Sc) secara teoritis diperoleh total pemampatan (Sc) sebesar 1,35 meter. dengan tinggi timbunan (Htimbunan) $7 \mathrm{~m}$.

$$
\begin{aligned}
\text { Yzmax } & =0.16 \times \text { Smax } \\
& =0.16 \times 1350 \\
& =216 \mathrm{~mm}
\end{aligned}
$$

Sehingga nilai $\mathrm{Y}=$ Yaktual $/ \mathrm{Ymax}$

$$
\begin{aligned}
& =123,400 / 216 \\
& =0.6 \leq 1.3(\mathrm{OK})
\end{aligned}
$$

Dari cek kestabilan tanah timbunan berdasarkan iclinomoter pada IN - 01 diketahui memenuhi kedua syarat kestabilan, sehingga tanah di titik tersebut dapat dikatakan dalam kondisi yang stabil. Perhitungan analisa cek kestabilan tanah timbunan pada titik inclinometer lainnya menunjukan kondisi tanah timbunan dalam kondisi yang stabil dapat dilihat pada Lampiran.

\section{E. Analisis Piezometer}

Syarat kestabilan piezometer adalah sebagai berikut :

$$
\Delta \mathrm{U} \leq \mathrm{I} \cdot \gamma \cdot \Delta \mathrm{H}
$$

Dimana:

$\Delta \mathrm{U}=$ variasi tegangan air pori tanah, diperoleh dari hasil bacaan pneumatic piezometer, $\mathrm{t} / \mathrm{m}^{2}$

dimana : $1 \mathrm{kPa}=0,102 \mathrm{t} / \mathrm{m}^{2}$

I $\quad=$ koefisien pengaruh $=1,0$

$\gamma=$ berat volume tanah timbunan. $\mathrm{t} / \mathrm{m}^{3}$

$\Delta \mathrm{H} \quad=$ variasi beban yang diterapkan di permukaan, $\mathrm{m}$

Tabel 8.

Hasil bacaan piezometer PP - 03

\begin{tabular}{|c|c|c|c|}
\hline Bacaan PP - 03 & $\begin{array}{c}\text { Tip 1 (-12m) } \\
(\text { kpa })\end{array}$ & $\begin{array}{c}\text { Tip 2 (-8m) } \\
(\text { kpa })\end{array}$ & $\begin{array}{c}\text { Tip 3 (-4m) } \\
(\text { kpa })\end{array}$ \\
\hline Umax & 117,30 & 82,80 & 55,20 \\
\hline Umin & 24,15 & 20,70 & 27,60 \\
\hline$\Delta \mathrm{U}$ & 93,15 & 62,10 & 27,60 \\
\hline
\end{tabular}

(Sumber : Hasil Analisa)
Dari Tabel 5.9 diperoleh $\Delta \mathrm{U}$ pada kedalaman $4 \mathrm{~m}$ sebesar 93,15 kpa, $8 \mathrm{~m}$ sebesar $61,10 \mathrm{kpa}$, dan $12 \mathrm{~m}$ sebesar 27,60 kpa. Selanjutnya untuk mengecek kestabilan pizometer PP 03 perlu adanya koefisien pengaruh yaitu sebesar 1.0 dan

\begin{tabular}{|c|c|c|c|}
\hline \multicolumn{4}{|c|}{ PP-03 } \\
\hline & $\Delta U(t / m 2)$ & I.y. $\Delta H$ & $\Delta U<$ I..$\Delta H$ \\
\hline$\Delta \mathrm{U1}$ & 2,4633 & 12,59825 & OK \\
\hline$\Delta U 2$ & 2,1114 & 12,59825 & OK \\
\hline$\Delta U_{3}$ & 2,8152 & 12,59825 & OK \\
\hline
\end{tabular}
berat volume tanah timbunan yaitu $1.75 \mathrm{t} / \mathrm{m} 3$. Satuan pada hasil bacaan Piezometer adalah kpa, maka perlu diubah menjadi t/m2 dengan cara dikalikan $0,102 \mathrm{t} / \mathrm{m} 2(1 \mathrm{kpa}=$ 0,102 tm2). Hasil cek kestabilan PP - 03 dapat dilihat pada Tabel 5.10

Tabel 9.

Hasil cek kestabilan PP - 03

(Sumber : Hasil Analisa)

Sehingga dapat diketahui bahwa cek kestabilan tanah timbunan berdasarkan piezometer memenuhi syarat kestabilan.

\section{F. Analisa Angka Keamanan (SF) Timbunan}

Pada proses penimbunan, akan dilakukan perhitungan SF dengan program bantu untuk mengetahui SF pada setiap penimbunan. Akan dilakukan perhitungan SF dengan kondisi asumsi belum adanya PVD menggunakan $\mathrm{Cu}$ lama dan kondisi setelah adanya PVD dengan menggunakan $\mathrm{Cu}$ baru.

1. Kondisi SF dengan $\mathrm{Cu}$ lama

Analisa stabilitas menggunakan $\mathrm{Cu}$ lama dilakukan untuk mengetahui nilai Safety Factor tanah timbunan sebelum adanya perbaikan tanah menggunakan PVD. Analisa SF ini dilakukan di seluruh titik Settlement Plate SP-05 hingga SP12. Pemampatan atau Sc dalam analisa ini diperoleh dari hasil Settlement Plate di lapangan.

Tabel 10.

Kondisi SF dengan $\mathrm{Cu}$ lama

\begin{tabular}{|c|c|c|c|c|c|}
\hline \multicolumn{7}{|c|}{ Kondisi SF dengan Cu lama } \\
\hline STA & SP & Hinisial timb & Settlement & SF & IN \\
\hline \multirow{4}{*}{$41+550$} & SP 05 & 7,2 & 1,6 & 0,608 & IN 01 \\
\cline { 2 - 6 } & SP 06 & 7,2 & 1,5 & 0,608 & IN 01 \\
\cline { 2 - 6 } & SP 07 & 7,2 & 1,47 & 0,608 & IN 02 \\
\cline { 2 - 6 } & SP 08 & 7,2 & 1,4 & 0,608 & IN 02 \\
\hline \multirow{4}{*}{$42+000$} & SP 09 & 7,1 & 1,4 & 0,619 & IN 03 \\
\cline { 2 - 6 } & SP 10 & 7 & 1,4 & 0,606 & IN 03 \\
\cline { 2 - 6 } & SP 11 & 7 & 1,2 & 0,613 & IN 04 \\
\cline { 2 - 6 } & SP 12 & 7 & 1,2 & 0,626 & IN 04 \\
\hline
\end{tabular}

(Sumber : Hasil Analisa)

\section{Kondisi SF dengan Cu baru}

Analisa stabilitas menggunakan $\mathrm{Cu}$ baru dilakukan untuk mengetahui nilai Safety Factor tanah timbunan setelah adanya perbaikan tanah menggunakan PVD. Analisa SF ini dilakukan di seluruh titik Settlement Plate SP-05 hingga SP12. Pemampatan atau Sc dalam analisa ini diperoleh dari hasil Settlement Plate di lapangan.

Tabel 11

Kondisi SF dengan $\mathrm{Cu}$ baru 


\begin{tabular}{|c|c|c|c|c|c|}
\hline STA & SP & Hinisial timb & Settlement & SF & IN \\
\hline \multirow{4}{*}{$41+550$} & SP 05 & 7,2 & 1,6 & 0,894 & IN 01 \\
\cline { 2 - 6 } & SP 06 & 7,2 & 1,5 & 0,894 & IN 01 \\
\cline { 2 - 6 } & SP 07 & 7,2 & 1,47 & 0,882 & IN 02 \\
\cline { 2 - 6 } & SP 08 & 7,2 & 1,4 & 0,882 & IN 02 \\
\hline \multirow{4}{*}{$42+000$} & SP 09 & 7,1 & 1,4 & 0,927 & IN 03 \\
\cline { 2 - 6 } & SP 10 & 7 & 1,4 & 0,941 & IN 03 \\
\cline { 2 - 6 } & SP 11 & 7 & 1,2 & 0,909 & IN 04 \\
\cline { 2 - 6 } & SP 12 & 7 & 1,2 & 0,909 & IN 04 \\
\hline
\end{tabular}

(Sumber : Hasil Analisa)

Berdasarkan Tabel 5.12 dan 5.13 diketahui adanya peningkatan SF dari kondisi belum adanya PVD (Cu lama) dan kondisi setelah pakai PVD ( $\mathrm{Cu}$ baru). Meskipun perhitungan sudah dilakukan dengan menggunakan $\mathrm{Cu}$ baru, nilai SF masih kurang dari SF rencana $=1,5$. Sehingga diperlukan perencanaan perkuatan lereng timbunan.

3. Perencanaan Perkuatan Lereng Timbunan

Perkuatan timbunan akan direncanakan pada luar timbunan dikarenakan adanya jalan di atas timbunan. Maka dari itu alternatif perkuatan yang digunakan adalah menggunakan micropile dan sheetpile. Dari perhitungan didapatkan 5 buah micropile dengan jarak $1 \mathrm{~m}$,diameter 600 $\mathrm{mm}$ dan panjang $13 \mathrm{~m}$ serta sheetpile tipe W-500-A-1000 sebanyak 5 buah

Tabel 13.

Perhitungan jumlah micropile dan sheetpile

\begin{tabular}{|c|c|c|c|c|c|c|}
\hline \multirow{3}{*}{ KETERANGAN } & \multirow{3}{*}{ SF min } & \multirow{3}{*}{ SF rencana } & \multicolumn{4}{|c|}{ JUMLAH PERKUATAN } \\
\hline & & & \multicolumn{2}{|c|}{ SHEETPILE BETON CORUGATED } & \multicolumn{2}{|c|}{ MICROPILE } \\
\hline & & & W-500-A-1000 & W-600-A-1000 & D $500 \mathrm{~mm}$ & $\mathrm{D} 600 \mathrm{~mm}$ \\
\hline \multirow{10}{*}{ MAT RENDAH } & 0,898 & \multirow{15}{*}{1,5} & 4,0552 & 3,1206 & 5,1315 & 3,4552 \\
\hline & 0,894 & & 4,3128 & 3,3189 & 4,7874 & 3,2236 \\
\hline & 0,921 & & 3,9837 & 3,0656 & 5,1964 & 3,4989 \\
\hline & 0,956 & & 2,9111 & 2,2402 & 6,2698 & 4,2217 \\
\hline & 0,948 & & 2,7419 & 2,1100 & 7,2036 & 4,8504 \\
\hline & 0,905 & & 3,7287 & 2,8694 & 5,4848 & 3,6932 \\
\hline & 0,920 & & 4,8767 & 3,7528 & 4,1054 & 2,7643 \\
\hline & 1,015 & & 4,2106 & 3,2402 & 4,0222 & 2,7083 \\
\hline & 0,927 & & 4,4091 & 3,3930 & 4,5397 & 3,0568 \\
\hline & 0,897 & & 4,2966 & 3,3064 & 4,6413 & 3,1252 \\
\hline \multirow{5}{*}{ MAT TINGGI } & 0,758 & & 2,1393 & 1,6463 & 4,0382 & 2,7191 \\
\hline & 0,767 & & 1,9414 & 1,4940 & 3,6646 & 2,4675 \\
\hline & 0,759 & & 2,2159 & 1,7052 & 4,1826 & 2,8163 \\
\hline & 0,772 & & 3,2065 & 2,4675 & 6,0525 & 4,0754 \\
\hline & 0,763 & & 2,6144 & 2,0119 & 4,9350 & 3,3229 \\
\hline \multicolumn{3}{|c|}{ perkuatan paling banyak } & 4,8767 & 3,7528 & 7,2036 & 4,8504 \\
\hline \multicolumn{3}{|c|}{ pembulatan } & 5 & 4 & 8 & 5 \\
\hline
\end{tabular}

VI. KESIMPULAN
Dari hasil analisis dan perhitungan yang telah dilakukan dapat ditarik kesimpulan sebagai berikut:

1. Kondisi tanah pada jalan tol Porong-Gempol paket 3A adalah sebagai berikut:

a. Kedalaman tanah lunak bervariasi yaitu 5 meter sampai dengan 17 meter

b. Kedalaman tanah keras berada pada kedalaman lebih dari 18-20 meter.

2. Stabilitas tanah timbunan yang dihitung dengan progam bantu diketahui bahwa nilai SF terkecil adalah 0,898; jadi angka keamanan di lapangan kurang dari SF rencana $(1,5)$ yang berarti timbunan dalam kondisi tidak aman atau kondisi kritis.

3. Kedalaman tanah keras berada pada bilitas tanah timbunan yang dihitung dengan progam bantu diketahui bahwa nilai SF terkecil adalah 0,898; jadi angka keamanan di lapangan kurang dari SF rencana $(1,5)$ yang berarti timbunan dalam kondisi tidak aman atau kondisi kritis.

4. Paket 3A tidak mengalami kelongsoran seperti paket 3B (berdasarkan analisa instrumen geoteknik) karena :

a. Semua titik settlement plate menunjukkan derajat konsolidasi lebih dari $90 \%$, yang berarti pemampatan tanah dasar di bawah timbunan sudah selesai.

b. Pengukuran muka air dalam piezometer mendukung hasil pembacaan dari settlement plate yang menunjukkan pemampatan tanah dasar sudah selesai.

c. Inclinometer tidak menunjukkan adanya bahaya longsor (tetap tegak) sehingga tanah timbunan dapat dikatakan aman.

5. Perkuatan lereng direncanakan dengan menggunakan sheetpile tipe W-500-A-1000 sebanyak 5 buah sedalam 13 meter atau micropile diameter $600 \mathrm{~mm}$ sebanyak 5 buah dengan kedalaman 13 meter.

\section{DAFTAR PUSTAKA}

[1] B. M. Das, Mekanika Tanah 1: Prinsip-Prinsip Rekayasa Geoteknik, Terjemahan. Surabaya: Erlangga, 1988.

[2] B. M. Das, Mekanika Tanah 2: Prinsip-Prinsip Rekayasa Geoteknik, Terjemahan. Surabaya: Erlangga, 1988. 